\title{
IL-10 and IL-10 receptor overexpression in oral giant cell lesions
}

\author{
Nárriman-Fátima-Lima Syrio ${ }^{1}$, Daniela-Rodrigues Faria ${ }^{2}$, Ricardo-Santiago Gomez ${ }^{3}$, Kenneth-John Gollob ${ }^{4}$, \\ Walderez-Ornelas Dutra ${ }^{2}$, Paulo-Eduardo-Alencar Souza ${ }^{1}$
}

\footnotetext{
${ }^{1}$ Laboratory of Oral Biology, School of Dentistry, Pontifícia Universidade Católica de Minas Gerais, Belo Horizonte-MG, Brazil

${ }^{2}$ Laboratory of Cell-Cell Interactions, Department of Morphology, Institute of Biological Sciences; Universidade Federal de Minas Gerais, Belo Horizonte-MG, Brazil

${ }^{3}$ Laboratory of Molecular Biology, Department of Clinical, Pathology and Surgery, School of Dentistry; Universidade Federal de Minas Gerais, Belo Horizonte-MG, Brazil

${ }^{4}$ Hospital Santa Casa, Graduate Program in Biomedicine, Belo Horizonte-MG, Brazil; SRI International Biosciences Division, Menlo Park, CA, USA
}

Correspondence:

Mestrado em Odontologia, prédio 46

Departamento de Odontologia da Pontifícia Universidade Católica de Minas Gerais,

Av. Dom José Gaspar, 500,

Bairro Coração Eucarístico,

CEP 30535-901, Belo Horizonte, Minas Gerais, Brazil

pauloalencar@pucminas.br

Syrio NF, Faria DR, Gomez RS, Gollob KJ, Dutra WO, Souza PE. IL-10 and IL-10 receptor overexpression in oral giant cell lesions. Med Oral Patol Oral Cir Bucal. 2011 Jul 1;16 (4):e488-92.

http://www.medicinaoral.com/medoralfree01/v16i4/medoralv16i4p488.pdf

Received: $27 / 02 / 2010$

Accepted: 26/08/2010

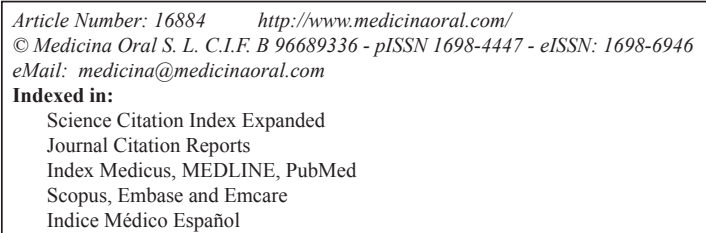

\begin{abstract}
Objective: Central giant cell lesions (CGCL) and peripheral giant cell lesions (PGCL) occur in the jaws and contain osteoclast-like giant cells and mononuclear cells positive for the macrophage marker CD68. The participation of immune-inflammatory mechanisms has been proposed in the lesions development. As IL-10 is one of the most important anti-inflammatory cytokines and it is also an inhibitory cytokine to macrophage function and bone resorption, the purpose of the present study was to investigate its expression together with its receptor (IL-10R $\alpha$ ) in CGCL and PGCL.

Study Design: Six fragments of CGCL and seven fragments of PGCL were obtained by surgical excision. Frozen specimens were cut and subjected to immunofluorescence staining using fluorescent-labeled anti-CD68, anti-IL10, and anti-IL-10R $\alpha$ monoclonal antibodies. Microscopic analyses were performed and the percentage of positive mononuclear and giant cells for each parameter was obtained.

Results: Our results revealed that all giant cells from CGCL and PGCL were CD68+ and IL-10R $\alpha+$ and that the majority was also positive for IL-10. More than $50 \%$ of the mononuclear cells from both lesions expressed IL$10 \mathrm{R} \alpha$ and the majority of these cells were CD68+ and IL-10+.

Conclusion: Considering that IL-10 has inhibitory effects on the pathologic processes related to the development of the oral giant cell lesions, the high frequencies of cells producing this cytokine seems contradictory to these lesions growth. Investigation about the production of inflammatory cytokines as well as the IL-10 signaling pathways in oral giant cell lesions is required to elucidate the immunopathology of CGCL and PGCL.
\end{abstract}

Key words: Giant cell granuloma, peripheral giant cell granuloma, interleukin-10, interleukin-10 receptor. 


\section{Introduction}

The central giant cell lesion (CGCL) is a reactive bone lesion that occurs most commonly in the anterior portion of the mandible of young patients (1). Radiologically, the lesions show an unilocular or a multilocular radiolucent lesion and presents a variable clinical behavior and unpredictable course. Some lesions show a slow growth and do not recur, while others exhibit rapid growth, root resorption, cortex perforation, and a tendency to recur after excision $(1,2)$.

The peripheral giant cell lesion (PGCL) is a relatively common reactive lesion that occurs on the gingiva or edentulous alveolar ridge, showing as a red or reddishblue nodular mass. Most lesions grow slowly, can develop at almost any age, and show highest prevalence in females. The development of PGCL is usually related to the presence of local irritating factors and arises from the connective tissue of the gingiva or the periosteum of alveolar ridge (3).

Histologically, both lesions are characterized by the presence of numerous multinucleated giant cells embedded in a fibrocellular stroma showing blood vessels, extensive hemorrhagic areas, and newly formed osteoid or bone $(1,4)$. Recently, it has been suggested that mononuclear cells from CGCL and PGCL comprise mainly osteoclast precursors, macrophages, and some osteoblastic cells (5). The giant cells from both lesions show phenotypic and functional characteristics of osteoclasts $(6,7)$. Previous studies have shown that the mononuclear cells from these giant cell lesions may be responsible for the formation of the giant cells $(7,8)$. However, the relationship of giant cells with mononuclear cells has not been fully elucidated.

The presence of osteoclast-like cells intermingled with mononuclear cells suggests that immune-inflammatory mechanisms may participate in the development of these lesions. Previous studies demonstrated alterations of the frequencies of circulating monocytes and lymphocytes that produce inflammatory and anti-inflammatory cytokines, including IL-10, in individuals with CGCL (9). IL-10 is one of the most important anti-inflammatory cytokines and it is also an inhibitory cytokine to macrophages function and bone resorption $(10,11)$. Based on the fact that circulating monocytes can be recruited from blood to inflammatory sites and on the fact that the production of cytokines in these sites represents an important mechanism of control of tissue local alterations (12), we investigated the expression of the immunossupressive cytokine IL-10 and its receptor (IL-10R $\alpha$ ) in mononuclear and giant cells from CGCL and PGCL.

\section{Materials and Methods}

Patients. Six cases of CGCL and seven cases of PGCL were analyzed in this study. The diagnosis, age, sex, location, size, radiographic aspects, and treatment of the samples are presented in (Table 1). All patients were volunteers, and informed consent was obtained from all individuals prior to collection of lesion material. Diagnosis of CGCL or PGCL was performed based on clinical, radiographic, and histopathological analysis. A fragment of each lesion obtained by surgical excision was maintained in a 30\% sucrose solution for approximately $30 \mathrm{~min}$ at $4 \mathrm{oC}$; then it was transferred to TissueTek $^{\circledR}$ O.C.T. ${ }^{\mathrm{TM}}$ Compound freezing medium (Sakura) and immediately placed in a $-20^{\circ} \mathrm{C}$ freezer for 1 hour. The material was stored at $-80^{\circ} \mathrm{C}$ until analysis. This study was approved by the local Ethical Committee.

Histological and immunofluorescence staining. Individual 4- to 5- $\mu \mathrm{m}$ cryosections were placed in salineprecoated slides (VWR Scientific) and fixed for $10 \mathrm{~min}$

Table 1. Clinical information on peripheral giant cell lesion (PGCL) and central giant cell lesion (CGCL) cases selected for the study.

\begin{tabular}{|c|c|c|c|c|c|c|c|}
\hline Patient & Diagnosis & $\begin{array}{c}\text { Age } \\
(\mathbf{y r})\end{array}$ & Sex & Location & $\begin{array}{c}\text { Size } \\
(\mathbf{m m})\end{array}$ & Radiographic aspects & Treatment \\
\hline 1 & CGCL & 11 & M & mandible & 30 & multilocular radiolucent lesion & curettage \\
\hline 2 & CGCL & 9 & F & mandible & 30 & multilocular radiolucent lesion & curettage \\
\hline 3 & CGCL & 46 & M & mandible & 40 & multilocular radiolucent lesion & curettage \\
\hline 4 & CGCL & 41 & F & mandible & 10 & unilocular radiolucent lesion & curettage \\
\hline 5 & CGCL & 11 & F & mandible & 40 & multilocular radiolucent lesion & curettage \\
\hline 6 & CGCL & 19 & M & mandible & 20 & bilocular radiolucent lesion & curettage \\
\hline 7 & PGCL & 57 & M & edentulous lower ridge & 10 & alveolar crest resorption & surgical excision \\
\hline 8 & PGCL & 37 & M & edentulous lower ridge & 20 & alveolar crest resorption & surgical excision \\
\hline 9 & PGCL & 21 & F & lower gingiva & 15 & none & surgical excision \\
\hline 10 & PGCL & 25 & F & lower gingiva & 30 & alveolar crest resorption & surgical excision \\
\hline 11 & PGCL & 22 & F & upper gingiva & 50 & none & surgical excision \\
\hline 12 & PGCL & 45 & M & edentulous upper ridge & 25 & none & surgical excision \\
\hline 13 & PGCL & 21 & M & lower gingiva & 20 & alveolar crest resorption & surgical excision \\
\hline
\end{tabular}


with acetone. Slides were incubated with phosphatebuffered saline for $15 \mathrm{~min}$ and subjected either to hematoxylin-eosin staining or to immunofluorescence using specific monoclonal antibodies. Standard hematoxylineosin staining was performed to ensure tissue integrity as well as for evaluation of the location of cellular areas containing giant cells. Immunofluorescence reactions involved incubation with fluorescein isothiocyanate (FITC)-labeled monoclonal antibody anti-CD68 (clone Ki-M7, Caltag, Burlingane, CA, 1:30 dilution) and phycoerythrin (PE)-labeled monoclonal antibodies anti-IL10 (clone JES3-9D7, Caltag, Burlingane, CA, 1:20 dilution). Sections were incubated with antibody mixtures overnight at $4^{\circ} \mathrm{C}$. For the IL-10R $\alpha$ staining, sections were incubated with monoclonal antibody anti-IL-10R $\alpha$ (clone 37607.11, R\&D Systems, Minneapolis, MN, 1:40 dilution) overnight at $4^{\circ} \mathrm{C}$, washed with phosphatebuffered saline, and incubated with rodamine-labeled antibody anti-mouse immunoglobulin (Jackson ImmunoResearch Laboratories, Inc - Pennsylvania, USA, 1:200 dilution) for 1 hour at room temperature. After staining, preparations were extensively washed with phosphate-buffered saline, counterstained with 4',6'diamidino-2-phenylindole (DAPI), and mounted using Hydromount (National Diagnostics). Slides were kept at $4^{\circ} \mathrm{C}$, protected from light, until acquisition in a laser scanning confocal microscope (Meta-510 Zeiss). Isotype controls were analyzed separately to confirm the lack of nonspecific staining.

Microscopy analysis. Imaging was performed with a Meta-510 Zeiss laser scanning confocal system running LSMix software with an oil immersion PlanApochromat objective (63X, 1.2 numerical aperture). A water-cooled argon UV laser $(488 \mathrm{~nm})$ or a neon laser was used to excite the preparation (through its $488 \mathrm{~nm}$ line or $543 \mathrm{~nm}$ line), and light emitted was selected with band-pass filters (20/80 for DAPI or 503/30 for FITC) or long-pass filter 560 for PE and rodamine. For each section, cellular areas containing giant cells were selected for analysis. Within these areas, a minimum of ten images (fields) was collected. Image analysis and processing were performed with LSMix, Confocal Assistant, Adobe Photoshop, and Image Tool software. Analyses were performed by counting the total number of mononuclear or giant cells in the ten fields acquired (DAPI stain cellular nucleus), the number of FITC or PE single-positive cells and the number of double-positive cells, for CD68 and IL-10 staining. For IL-10R $\alpha$ staining, the total number of cells and the number of rodamine-positive cells were obtained. The counts were performed blindly, the results were expressed as the percentage of positive mononuclear and giant cells per section for each parameter for each patient, and then the values were averaged for each group.

Statistical analysis. Statistical analysis of the data was performed using BioEstat 3.0 statistical software. The comparisons of percentage for a given parameter between the groups were performed using the nonparametric Mann-Whitney test. Correlation analysis between the percentage of IL-10+ cells and IL-10R $\alpha+$ cells into each group was performed using the Spearman test. Results were considered statistically different when the analysis returned a $\mathrm{P}$ value of $<0.05$.

\section{Results}

High frequencies of mononuclear and giant cells from CGCL and PGCL express IL-10. Evaluation of IL-10 expression by mononuclear and giant cells from CGCL and PGCL were performed by microscopy analysis of sections submitted to immunofluorescence reactions, as described in Materials and Methods. The average number of total cells counted was 27 for giant cells and 747 for mononuclear cells in each case. Mononuclear and giant cells from both lesions express IL-10 (Fig. $1 \mathrm{~A}$ and $\mathrm{B})$. More than $80 \%$ of the mononuclear cells in CGCL and approximately $100 \%$ of the mononuclear cells in PGCL were IL-10+ (Table 2). Approximately $80 \%$ of the giant cells in CGCL and $100 \%$ of giant cells in PGCL were IL-10+. All giant cells from both lesions were CD68+. High frequencies of CD68+ mononuclear cells were observed in CGCL and PGCL groups (Table 2).

Evaluation of the cellular sources of IL-10 demonstrated that CD68+ mononuclear cells are the main cell population expressing this cytokine in both CGCL and PGCL (Table 2). Whereas the total expression of IL-10 was not
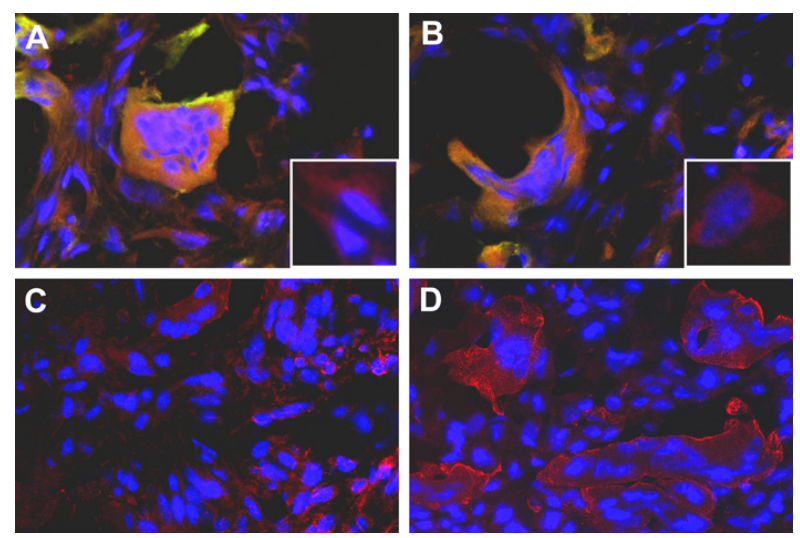

Fig. 1. Expression of IL-10 and IL-10R $\alpha$ in CGCL and PGCL cases. (A and B) Representative images from confocal microscopy analyses of CD68 and IL-10 expression in CGCL and PGCL cases respectively. Overlays for CD68 (green), IL-10 (red), and DAPI (blue) are shown, with inset of high-power detail of IL-10 positive mononuclear cells. Cells that are double positive for CD68 and IL-10 show a yellow or orange-red cytoplasm. (C and D) Representative images from confocal microscopy analyses of IL-10R $\alpha$ expression in CGCL and PGCL cases respectively. Overlays for IL-10R $\alpha$ (red) and DAPI (blue) are shown. 
Table 2. Percentage of IL-10-, CD68-, and IL-10R $\alpha$-positive mononuclear cells and relative contribution of the CD68+ population to the production of IL-10 in central giant cell lesion (CGCL) and peripheral giant cell lesion (PGCL) cases.

\begin{tabular}{|l|c|c|c|c|c|c|c|c|c|}
\hline \multicolumn{1}{|c|}{ Parameter } & \multicolumn{4}{c|}{ CGCL (n=6) } & \multicolumn{4}{c|}{ PGCL (n=7) } & \\
\hline & Mean & Median & Minimum & Maximum & Mean & Median & Minimum & Maximum & P value \\
\hline \% total IL-10+ cells & 80.0 & 91.6 & 14.3 & 99.7 & 98.8 & 100 & 95.4 & 100 & 0.032 \\
\hline \% total CD68+ cells & 81.5 & 90.9 & 34.4 & 96.0 & 97.8 & 99.7 & 92.9 & 100 & 0.010 \\
\hline \% IL-10+ in CD68+ cells & 86.5 & 97.6 & 31.5 & 100 & 99.9 & 100 & 99.8 & 100 & 0.030 \\
\hline \% total IL-10R $\alpha+$ cells & 60.6 & 63.4 & 26.4 & 92.4 & 67.4 & 66.2 & 39.1 & 84.2 & 0.886 \\
\hline
\end{tabular}

statistically different when CGCL and PGCL were compared, the frequency of IL-10+ cells in CD68+ mononuclear population was higher in PGCL than CGCL group (Table 2).

High frequencies of mononuclear and giant cells from CGCL and PGCL express IL-10R $\alpha$. Evaluation of IL$10 \mathrm{R} \alpha$ expression by mononuclear and giant cells from CGCL and PGCL was performed by microscopy analysis of sections submitted to immunofluorescence reactions, as described in Materials and Methods. Mononuclear and giant cells from both lesions express IL-10R $\alpha$ (Fig. 1C and D). While all giant cells in CGCL and PGCL express IL-10R $\alpha$, approximately $60 \%$ of mononuclear cells in both lesions were positive for IL-10R $\alpha$ (Table 2).

\section{Discussion}

In this work, we demonstrate that cells from central giant cell lesion (CGCL) and peripheral giant cell lesion (PGCL) are able to produce the anti-inflammatory cytokine IL-10 and to express the IL-10R $\alpha$. When we quantified the cells that produce IL-10 in the lesions, we observed that most of the mononuclear and giant cells from CGCL and almost all cells from PGCL were IL-10 producers.

IL-10 is one of the most important anti-inflammatory cytokines, exerting a high inhibitory activity on macrophage function (10). Many mononuclear cells from CGCL and PGCL show characteristics of macrophages or osteoclast precursors and these cells do not show strong proliferative activity $(5,13)$. As the lesions are continuously developing and the osteoclast precursors are recruited from the blood (14), the increasing celullarity of the lesions depends directly on the recruitment of monocytic cells from the blood. The macrophages produce chemokines and cytokines that stimulate the expression of adhesion molecules by the endothelial cells (15). These phenomena are essential for the leukocyte recruitment from the blood to the inflammatory sites. IL-10 inhibits production of these chemokines and cytokines by macrophages, thus decreasing the cell recruitment from peripheral blood (10).

In addition to IL-10 inhibitory effects on leukocyte re- cruitment, IL-10 also inhibits M-CSF production (10). The M-CSF is a key mediator of differentiation of osteoclasts precursors in mature osteoclasts (14). The inhibition of the macrophages functions by IL-10 leads to the suppression of the production of IL-12, a cytokine that stimulates T lymphocytes to produce IFN- $\gamma$, which is the main macrophage activating factor (16). In vitro studies demonstrated that the mononuclear cells from human blood only form multinucleated giant cells in the presence of IFN- $\gamma$. IFN- $\gamma$ induces the expression of the adhesion molecule LFA-1 by the monocytic cells. This molecule is necessary for the fusion and formation of giant cells (17).

IL-10 inhibits the proliferation and differentiation of osteoclasts precursors in murine mononuclear cells culture, even in the presence of osteoblasts (11). This cytokine also inhibits the production of cytokines that stimulate bone resorption, such as IL-1, IL-6 and TNF- $\alpha$, by the macrophages (10).

The high frequency of cells that produce IL-10 in the CGCL and in the PGCL may reflect an attempt to inhibit the mechanisms that lead to the uncontrolled recruitment of mononuclear cells and to the destruction of tissue. It is possible that the cells from CGCL and PGCL produce high levels of pro-inflammatory cytokines. Thus, monocytic cells recruited from the blood to the lesion sites could respond to these stimuli by producing IL-10. Certainly, many soluble factors are involved in the development of CGCL and PGCL, in which the production of IL-10 by itself is not sufficient to assure the modulation of the pathologic process related to the pathogenesis of these lesions.

The elevated frequencies of IL-10 positive cells in both lesions (more than $80 \%$ ) are significantly higher than the ones observed in active infectious lesions as in mucosal leishmaniasis (18). As CGCL and PGCL have an unknown etiology, we do not know which stimuli lead to the macrophages activation, inducing IL-10 production.

Concerning the contribution of the CD68+ population to the total production of IL-10, we observed that this population is the main source of IL-10 in both lesions studied. In the present study, $20 \%$ of the CGCL mononuclear cells and $2 \%$ of the PGCL cells were CD68 
negative. These cells may be another leukocyte type or osteoblastic cells, as previously described by other authors $(5,6)$. About $50 \%$ of the CD68 negative mononuclear cells from both, CGCL and PGCL, produce IL-10 (data not showed). T and B leukocytes, NK cells and osteoblasts also produce IL-10 $(10,19)$. It is possible that soluble factors present in the lesions stimulate other cell types to produce IL-10.

In order to investigate whether CGCL and PGCL cells are able to respond to IL-10, we evaluated the IL-10R $\alpha$ expression. All giant cells and about $60 \%$ of mononuclear cells from both lesions were IL-10R $\alpha$ positive. This receptor is expressed by a variety of cells of the immune system, especially by macrophages (20), but there are no studies about the expression of this receptor by giant cells or osteoclasts. Our findings suggest that most cells from both lesions (CGCL and PGCL) are able to respond to the IL-10, although the strong inhibitory action of IL-10 does not correspond with the development of these lesions. The mechanisms that control the expression of the IL-10R $\alpha$ are not well established. Considering that IL-10 has inhibitory effects on the pathologic processes related to the development of the oral giant cell lesions, the high frequencies of cells that produce this cytokine seems contradictory to these lesions' growth. One possibility is that the lesion cells present alterations on their molecular signaling pathway activated by the IL-10. Another possibility is that the production of pro-inflammatory cytokines is sufficiently high to supplant the inhibitory effects of IL-10. Investigation about the production of inflammatory cytokines as well as the IL-10 signaling pathways in oral giant cell lesions is required to elucidate the immunopathology of CGCL and PGCL.

\section{References}

$$
\text { References with links to Crossref - DOI }
$$

1. Whitaker SB, Waldron CA. Central giant cell lesions of the jaws. A clinical, radiologic, and histopathologic study. Oral Surg Oral Med Oral Pathol. 1993;75:199-208.

2. Chuong R, Kaban LB, Kozakewich H, Perez-Atayde A. Central giant cell lesions of the jaws: a clinicopathologic study. J Oral Maxillofac Surg. 1986;44:708-13.

3. Chaparro-Avendaño AV, Berini-Aytés L, Gay-Escoda C. Peripheral giant cell granuloma. A report of five cases and review of the literature. Med Oral Patol Oral Cir Bucal. 2005;10:53-7; 48-52.

4. Gandara-Rey JM, Pacheco Martins Carneiro JL, Gandara-Vila $\mathrm{P}$, Blanco-Carrion A, García-García A, Madriñán-Graña $\mathrm{P}$, et al. Peripheral giant-cell granuloma. Review of 13 cases. Med Oral. 2002;7:254-9.

5. Itonaga I, Hussein I, Kudo O, Sabokbar A, Watt-Smith S, Ferguson $\mathrm{D}$, et al. Cellular mechanisms of osteoclast formation and lacunar resorption in giant cell granuloma of the jaw. J Oral Pathol Med. 2003;32:224-31.

6. Liu B, Yu SF, Li TJ. Multinucleated giant cells in various forms of giant cell containing lesions of the jaws express features of osteoclasts. J Oral Pathol Med. 2003;32:367-75.

7. Flanagan AM, Nui B, Tinkler SM, Horton MA, Williams DM, Chambers TJ. The multinucleate cells in giant cell granulomas of the jaw are osteoclasts. Cancer. 1988;62:1139-45.
8. Bonetti F, Pelosi G, Martignoni G, Mombello A, Zamboni G, Pea $\mathrm{M}$, et al. Peripheral giant cell granuloma: evidence for osteoclastic differentiation. Oral Surg Oral Med Oral Pathol. 1990;70:471-5.

9. De Souza PE, Gomez RS, Xavier GM, Dos Santos JS, Gollob KJ, Dutra WO. Systemic leukocyte activation in patients with central giant cell lesions. J Oral Pathol Med. 2005;34:312-7.

10. Spits H, De Waal Malefyt R. Functional characterization of human IL-10. Int Arch Allergy Immunol. 1992;99:8-15.

11. Hong MH, Williams H, Jin CH, Pike JW. The inhibitory effect of interleukin-10 on mouse osteoclast formation involves novel tyrosine-phosphorylated proteins. J Bone Miner Res. 2000;15:911-8.

12. Romagnani S. Cytokines and chemoattractants in allergic inflammation. Mol Immunol. 2002;38:881-5.

13. Souza PE, Mesquita RA, Gomez RS. Evaluation of p53, PCNA, Ki-67, MDM2 and AgNOR in oral peripheral and central giant cell lesions. Oral Dis. 2000;6:35-9.

14. Katagiri T, Takahashi N. Regulatory mechanisms of osteoblast and osteoclast differentiation. Oral Dis. 2002;8:147-59.

15. Vaddi K, Newton RC. Regulation of monocyte integrin expression by beta-family chemokines. J Immunol. 1994;153:4721-32.

16. Fiorentino DF, Zlotnik A, Mosmann TR, Howard M, O'Garra A. IL-10 inhibits cytokine production by activated macrophages. J Immunol. 1991;147:3815-22.

17. Möst J, Neumayer HP, Dierich MP. Cytokine-induced generation of multinucleated giant cells in vitro requires interferon-gamma and expression of LFA-1. Eur J Immunol. 1990;20:1661-7.

18. Faria DR, Gollob KJ, Barbosa J Jr, Schriefer A, Machado PR, Lessa $\mathrm{H}$, et al. Decreased in situ expression of interleukin-10 receptor is correlated with the exacerbated inflammatory and cytotoxic responses observed in mucosal leishmaniasis. Infect Immun. 2005;73:7853-9.

19. García-López S, Meikle MC, Villanueva RE, Montaño L, Massó F, Ramírez Amador V, et al. Mechanical deformation inhibits IL-10 and stimulates IL-12 production by mouse calvarial osteoblasts in vitro. Arch Oral Biol. 2005;50:449-52.

20. Moore KW, De Waal Malefyt R, Coffman RL, O’Garra A. Interleukin-10 and the interleukin-10 receptor. Annu Rev Immunol. 2001;19:683-765

\section{Acknowledgments}

This investigation received financial support from FAPEMIG (Fundação de Amparo à Pesquisa do Estado de Minas Gerais) \# 2026/03 and \# 454/07. R.S.G., K.J.G., and W.O.D. are CNPq/MCT fellows, and N.F.L.S. and D.R.F. are CAPES fellows. 